\title{
AN APPRECIATIVE VIEW OF HUMAN PERFORMANCE TECHNOLOGY
}

Jennifer Rosenzweig, CPT $\mid$ Darlene M. Van Tiem, CPT

\begin{abstract}
Human performance technology has been successful in resolving organizational issues and prompting a variety of business improvements. Yet there are times when the problemcentered approach is not sufficient. Instead, attention to organizational strengths and a focus on creating and building a positive vision for the future represent a better strategy. This article looks at a new variation on the consulting model-HPT: Appreciative Approach.
\end{abstract}

BETH WAS FRUSTRATED. As the lead consultant for a large-scale performance improvement project, she had anticipated seeing significant results at this stage of the initiative. The team had conducted a rigorous analysis, had identified several root causes, and had designed what she believed was an innovative solution with tremendous potential. Yet things were not working. People seemed to be clinging to old behaviors, and worse yet, her project team appeared ready to abandon their goals. The problems that sparked the project were feeling bigger and threatened to drag everyone down with them.

Have you ever experienced this dilemma? Have you ever led a project where your plans looked wonderful on paper, but reality appeared to have different ideas? What you may have been experiencing was the trap of inquiry: that what we ask questions about tends to grow. It was this insight, combined with several others, that led to the breakthrough discipline of appreciative inquiry. Appreciative inquiry (AI) is

the art and practice of asking questions that strengthen a system's capacity to apprehend, anticipate, and heighten positive potential. It centrally involves the mobilization of inquiry through the crafting of the "unconditional positive question" often-involving hundreds or sometimes thousands of people. In Al, the arduous task of intervention gives way to the speed of imagination and innovation; instead of negation, criticism, and spiraling diagnosis, there is discovery, dream, and design. (Cooperrider and Whitney, 1998, p. 3)
AI evolved from work done by David Cooperrider and Suresh Srivastva of Case Western Reserve University. The two researchers were conducting developmental work with a team and observed that greater energy and innovation emerged as the team examined their greatest strengths, both personally and organizationally. This, in turn, helped spark the needed changes. Cooperrider and Srivastva's study of this phenomenon evolved into what is now described as appreciative inquiry.

While Human Performance Technology (HPT) stands alone as an effective methodology with proven practices, situations arise that can benefit from the additional dimension that appreciative thought and deep inquiry offer. We therefore propose an alternative view, described as HPT: Appreciative Approach, which embraces the best of the existing HPT model in combination with insights from appreciative inquiry.

This article offers a brief review of AI and then paints a picture of how a performance improvement consultant can combine the two disciplines to create greater organizational impact.

\section{APPRECIATIVE INQUIRY - WHAT IS IT?}

As AI has grown in concept and practice, it has borrowed from the best thinking in organizational development, psychology, sociology, leadership theory, and other disciplines. Hammond (1998) describes a series of foundation principles in her The Thin Book of Appreciative Inquiry: 
Assumption 1: Finding What Works. Even the most troubled organizations have people, processes, or practices that work. Identifying and uncovering these assets offers insight and a foundation for progress.

Assumption 2: Choosing the Right Focus. What we focus on grows. Appreciative inquiry therefore suggests that framing our research and analysis on an affirmative view of the situation we face is critical.

Assumption 3: Creating Reality. Reality is a function of the world we live in as well as the insights and experiences we bring to the world. Reality is unique for each of us, and many realities can coexist.

Assumption 4: Asking the Right Questions. If we believe that what we focus on grows, then the questions we ask become the starting point for our future. As David Cooperrider says, "The seeds of change are implicit in the first questions asked" (Cooperrider, Whitney, \& Stavros, p. 32).

Assumption 5: Carrying the Past Forward. The journey of change becomes less threatening when we bring with us the comfort of ideas and practices we know and trust.

Assumption 6: Carrying the Best of the Past. Following the affirmative thread, if we're going to retain parts of the past as we journey into the future, it makes sense to keep those that represent our greatest strengths.

Assumption 7: Valuing Differences. Our differences, represented by our unique realities, offer innovation and many possibilities for building the future we most desire.

Assumption 8: Using Positive Language. Language drives our thought and action. It is therefore important to consider the words we choose, particularly the framing of the questions we ask (p. 20-21).

Many people know of AI through its practical application, best expressed through the 4-D model, shown in Figure 1.

Appreciative action begins at the center of the model, in which the affirmative topic choice is selected. This is the outward expression of "what we focus on grows." The topic is the starting point and suggests a direction for the future. And following the importance of language, the words themselves are a powerful component. For example, would you like to study a project that centers on addressing issues of customer dissatisfaction? Or would you prefer to explore creating the magic of lasting guest relationships?

Discovery then becomes the first phase of the model. This centers on inquiry and dialogue and uncovers the

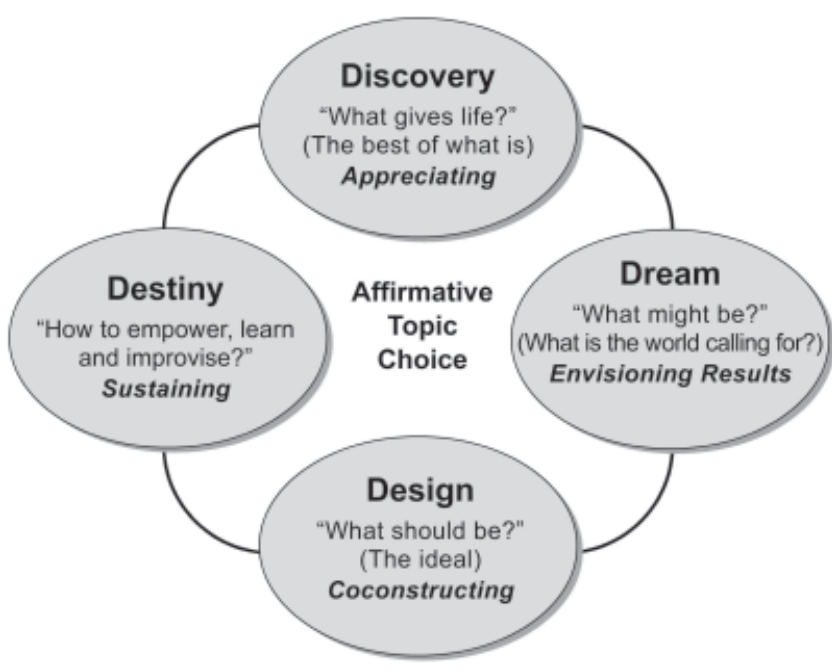

Source: Cooperrider \& Whitney, 1998, p. 30.

FIGURE 1. THE 4-D MODEL

best of the organization as it relates to the topic. Interviews and stories are used to gather data, and as many organizational voices as possible are included.

Dream is the springboard for future thought and vision. Participants are encouraged to imagine the world they would choose to live in, without regard to current problems and challenges. As imaginations expand, vivid images of the organization's potential start to emerge, fueled by what is already successful and valued.

Design begins to bring in the structure and prompts the decisions that precipitate action. Many ideas start to combine, and teams organize them into specific descriptions of their intended future, called provocative propositions. Through these propositions, more concrete intentions are captured and organized into a common point of view that leads the way to new actions and results.

Destiny brings it all to life. Teams and individuals identify the needed changes and take ownership for building the future. Although this looks like more traditional project development, the resulting work takes on its own energy and life when built on a platform of strengths and a clear vision for a mutually desirable future.

Appreciative inquiry is often experienced through a summit, in which the organization's stakeholders come together to discover, dream, and design (Cooperrider, Whitney, \& Stavros, 2003). The intention is to bring the entire organization together, from employees to customers to suppliers (and potentially even members of the local community). Through rich and diverse dialogue, the organization's potential can emerge, leading to profound change. 


\section{HPT AND AI: AN APPRECIATIVE APPROACH}

An examination of the HPT model (Van Tiem, Moseley, \& Dessinger, 2004) reveals a number of opportunities for reframing the methodology. Doing so resulted in our model, HPT: Appreciative Approach. This section highlights the distinctions between HPT and AI.

\section{Performance Analysis: Discover the Positive Core}

One of the most powerful aspects of $\mathrm{AI}$ is in the inquiry: asking questions that uncover the strengths and values as well as the shared future vision.

The analysis stage of the HPT model was a key opportunity for consideration. This resulted in two primary changes: the addition of a positive experience analysis as well as a reframing and conversion of the cause analysis into a strengths analysis. The positive experience analysis is an important addition that expands the data collection to include insights at the individual level, especially those of a positive nature. The relationship between environmental and behavioral insights is then examined from a strengths perspective, expanding the knowledge relative to previous successes uncovered during the performance analysis.

\section{Distance Analysis: Dream}

In line with Cooperrider's emphasis on dreaming, the next phase leads to a description of the ideal workforce performance (the desired workforce performance) as compared to the current (or actual) workforce performance. The difference between the two is not earmarked as a gap because gap refers to deficits; instead, it is seen as a distance between the two, creating a positive path for moving into the future. Distance analysis visualizes the future and sets the stage for design.

\section{Intervention Selection, Design, and Development: Design}

Up to this point, the positive nature of the organization, society, the competition, the work, and workers has been

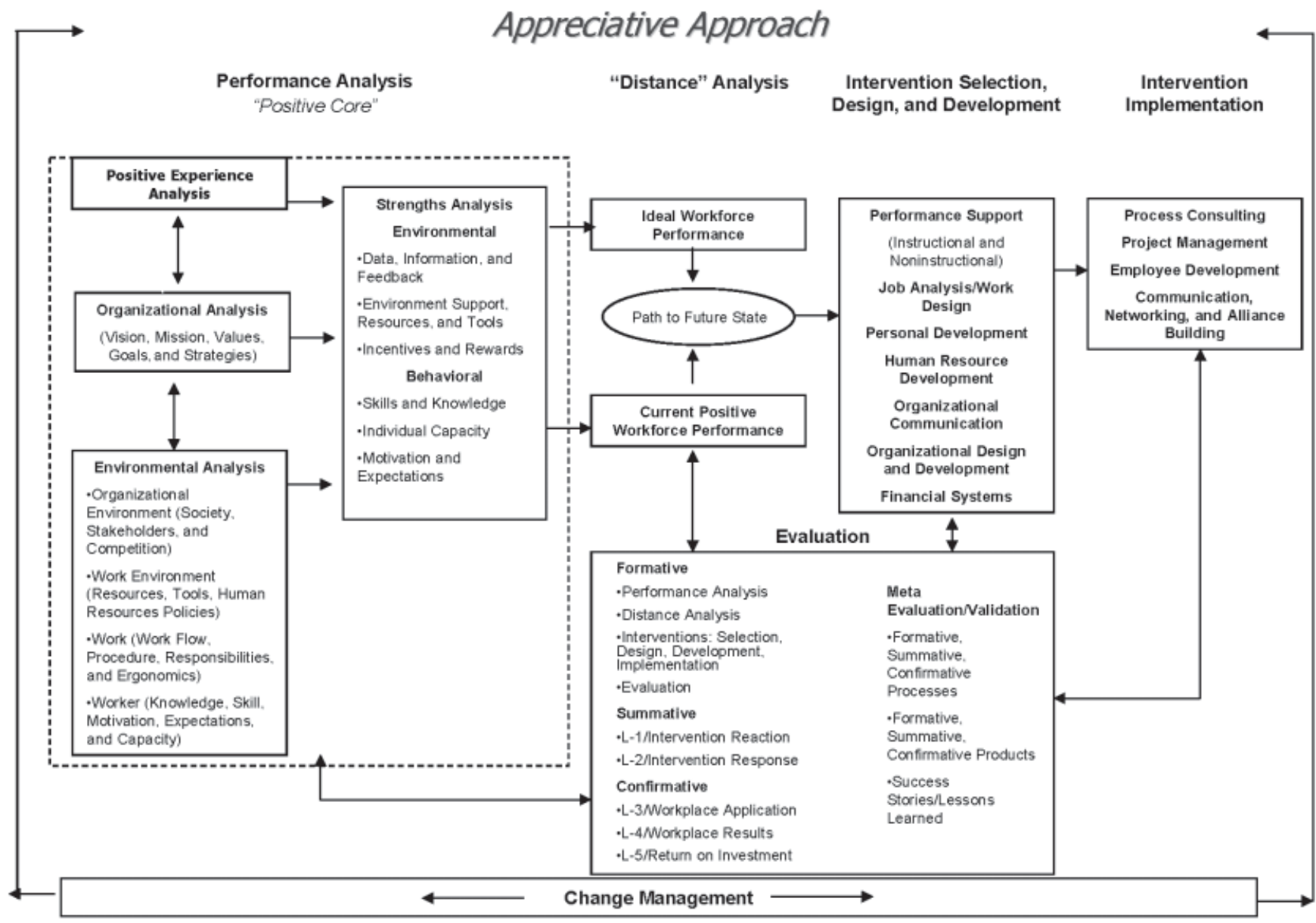

$L=$ Level

Source: Adapted from Van Tiem, Moseley, \& Dessinger, 2004, p. 3.

FIGURE 2. HUMAN PERFORMANCE TECHNOLOGY MODEL: APPRECIATIVE APPROACH 
considered to understand the baseline positive core. In addition, there is a vision of the future, a dream of the potential. Design remains largely unchanged at this point. HPT offers a rich repertoire of solutions to consider as the future state is imagined. The possibilities for positive impact are limitless; creativity and a willingness to try new things should expand the options.

\section{Intervention Implementation: Destiny}

The implementation stage (known as destiny in AI) remains intact, but with one exception. In the Van Tiem, Moseley, and Dessinger HPT model (2004), change management is considered to be during this later stage of the model. However, if we believe (as AI believes) that change happens when we begin asking the first questions, then change management becomes a consideration through the entire process and serves as a foundation element, as documented along the bottom of the matrix in Figure 2. In addition, HPT: Appreciative Approach involves process planning to prepare for the new and improved environment, produce detailed project plans to think through the obstacles and prepare to accommodate them, and consider all of the stakeholders who will be involved in a secondary, as well as a primary, way. Often overlooked, communication is critical and needs several media and messages to prepare all those who are involved and to generate excitement about the positive changes. Performance improvement professionals rely on their networks and alliances to provide ideas and feedback enabling their effort to be a success. For example, colleagues may have experienced similar efforts and can provide guidance about the most successful aspects and lessons learned.

\section{Evaluation}

Finally, evaluation remains a critical component of the overall effort to gauge progress and determine where the value lies. Most of the HPT evaluation approach remains similar. However, since stories are a critical element to discovering strengths, success stories are combined with lessons learned as a means to uncover the best of what is happening in a given organization. In addition, confirmative evaluation focuses on the positive outcomes resulting from the change effort: attaining competence, attaining effectiveness, and return on investment.

\section{BRINGING THE APPRECIATIVE APPROACH TO LIFE}

Since HPT is based on a deficit mind-set, most performance technology professionals will gradually move from problems to positive opportunities (Lewis \& Van Tiem, 2004). A case study illustrates AI's potential.

\section{HPT: Appreciative Approach ... embraces the best of the existing HPT model in combination with insights from appreciative inquiry.}

A recent application of HPT: Appreciative Approach occurred with a large private company that found itself in a down cycle: revenue loss was leading to downsizing and the resulting consequences of employee retention and low morale. A performance analysis uncovered a variety of concerns, ranging from maturing products to high overhead and administrative costs. However, the performance analysis also revealed a number of important organizational values and strengths:

- The organization had many talented individuals whose skills were not being sufficiently tapped.

- Customer satisfaction was a hallmark and continued to remain high despite the organizational distress.

- Many people placed a high value on the relationships they had within the company.

It was the strengths that inspired the resulting solution and related goals. The analysis team sought a solution that would

- Generate enthusiasm and participation

- Promote team engagement

- Encourage creative thinking

The HPT team created a team-based idea-generation event. Teams of 10 people each would be randomly formed from across the company, each charged with identifying the issues they felt were most pressing to the organization's growth. They would then be tasked with designing any solution they chose. To encourage participation and keep the pressures of daily work from limiting involvement, a day was set aside to conduct the brainstorming sessions. The resulting event was called a "Think-a-Thon."

Once the initial idea formed, it took on a life of its own. A communications campaign and two training programs were designed to support the effort. In addition, a budget for rewarding the top ideas was established, adding further motivation and excitement. Finally, the HPT team wanted to make the day as memorable as possible, so a closing 
celebration on the evening of the Think-a-Thon was added to the mix. As all the elements were developed, the underlying intention was to maximize the investment of time and talent by the organization while making the experience fun and festive.

To kick off the Think-a-Thon, the HPT team devised an all-company announcement as part of a quarterly business meeting. The centerpiece of the presentation was identifying the random teams. A social hour was hosted afterward to encourage team members to get acquainted and begin their brainstorming preparations.

Regular email announcements soon followed, themed with the phrase, "Let the Brain Games Begin!" These messages included a mix of information as well as teasers to promote active participation. As the day of the event approached, the creative dialogue increased, and many groups were finding time to engage in preliminary brainstorming sessions.

\section{HPT offers a rich repertoire of solutions to consider as the}

\section{future state is imagined.}

On the day of the Think-a-Thon, all work stopped until noon. Every conference room and open space was stocked with flip chart paper, brainstorming toys, and snacks. Breakfast was served, and at 9:00 A.M., the brain games began.

At noon, the sessions concluded, and all teams had an hour to submit the results of their labor for a preliminary round of judging that took place until midafternoon. The judges were tasked with identifying the most creative, the most client-friendly, and the most cost-effective ideas. Other awards were also created, including "best dressed" and "most spirited." These were considered preliminary awards with the intent of recognizing the talent and hard work of the organization. (All ideas went through deeper scrutiny in the following weeks.) Late in the afternoon, nearly 200 people gathered to hear highlights of the day's work, be recognized for their outstanding performance, and enjoy the company of good friends.

\section{Think-a-Thon Results}

Analysis of the entire effort was conducted, and the results were described as outstanding. From an organizational perspective, Think-a-Thon was perceived as successful. There were many new ideas to present to clients; relationships were strengthened, leading to more effective project teams; and team members realized the value of each department's contribution. Teams reported having a greater understanding of the entire organization. Metrics around idea generation were very favorable. Idea generation exceeded expectations by more than fivefold (initial estimates were that 30 new ideas would be generated). In addition, the organization went from identifying four employee-generated ideas for the first 11 months of 2005 to finishing the year with 167 ideas from the Think-aThon. Forty-one ideas were assigned to move forward very quickly, meaning that the teams needed to continue planning for implementation.

One unexpected finding was the submission of solutions for past problems that had already been resolved. Leadership was unaware that a variety of communications and training initiatives had missed some of their target audience. In essence, the Think-a-Thon had also served as a way to uncover the status of previous performance improvement solutions and reveal gaps in sustainability. As a result, fresh communications as well as a reprise of key training programs were rolled out soon after the event.

\section{Estimating Program Value}

The cost to conduct the event was $\$ 97,000$, including all labor for development and participation. Of the labor costs of $\$ 86,000$, approximately half was contributed as voluntary overtime (work performed during the lunch hour or after work). It should be noted that all standard business was executed and completed as anticipated during the extended Think-a-Thon time period.

It was initially anticipated that the program value would be linked exclusively to the quality of the resulting ideas, and program measurement was therefore designed with this in mind. However, it soon became clear to leadership that the real value of the Think-a-Thon was tied to the greater teamwork and positive energy that emerged. As expressed by one of the two sponsors, "The improvement in teamwork and enthusiasm has more than paid for the program investment; the ideas themselves are just a bonus!"

This realization led to an expansion of the program measures following the completion of the event. Interviews were conducted with six of the nine top leaders in the organization to determine the impact and value of the qualitative benefits. The approach for the analysis was designed based on Brinkerhoff's success case method (2003). With this method, stories and examples of successful application of the intended change are identified and reviewed. The value that is uncovered is then estimated and becomes a contributor to the return on investment determination.

As a result of this analysis, leadership gave examples of increases in the following behaviors and attitudes during and after the Think-a-Thon: 
- Organizational buzz and morale

- Networking

- Interteam collaboration for problem solving

- Participation in discretionary-time projects such as community service and company spirit events

- Appreciation for the challenges that other team members face

- Belief that their voice is important and will be heard by leadership

- Sense of ownership and commitment to the business

- Use of creativity and brainstorming techniques

One story that was shared concerned an employee who was a valued performer but tended to focus only on her assigned tasks. She rarely attended company social events and had avoided participation in community service activities organized by the company. The concern was that she was missing out on opportunities to develop relationships that could enhance her work experience and strengthen her bond with the organization. The Think-aThon was such a fun and productive experience for her that she promptly volunteered to lead a committee for the next charitable event.

Each of the leaders was also asked to put a dollar value on the impact of the Think-a-Thon. Various strategies were applied; for instance, one manager believed that the increase in enthusiasm and the stronger relationships would encourage people who might otherwise be seeking employment elsewhere to stay with the organization. She estimated that $1 \%$ of the organization (or two and a half people) would be affected by this. A turnover cost of $\$ 50,000$ per person was calculated, which is made up of reduced productivity, lost tacit knowledge, increases in errors during the transition phase, and administrative costs. The $\$ 50,000$ in savings multiplied by two and a half people resulted in an anticipated savings of $\$ 125,000$ as estimated by one of the leaders.

Beyond the qualitative impact, approximately $12 \%$ of the ideas submitted have been implemented. The ideas themselves covered a wide range of needs. For example, a recommendation to make an adjustment to the travel and expense form resulted in simplification of the process without loss of needed data. Another idea was to design a better way to communicate incremental changes in the common processes.

Many of the suggestions were considered intangible in terms of assessing their value, which made them difficult to measure. To resolve this, a modest financial benefit was attributed to each idea, using lowest-commondenominator estimates by people who had knowledge of the circumstances (for example, human resources and accounting worked on the travel and expense form proj-

\section{The more positive our images, thoughts, and dreams, the} more we are likely to have positive and enriching experiences.

ect). This resulted in an estimated total savings of $\$ 90,000$ that was conservatively attributed to the sum of ideas implemented.

If the return on investment had been calculated based on the idea generation alone, the project would have been seen by the leadership team as close to break-even. However, when adding the estimated turnover savings to their estimates about the monetary value of improved productivity, morale, and other intangibles, leadership defined the program's impact to be conservatively worth $\$ 400,000$. Other influences on achieving these perceived cost benefits were not captured in this evaluation process.

Finally, when these financial benefits are combined with the positive reviews and good feelings that were generated, the Think-a-Thon will be making a return appearance in the future.

From a practitioner's perspective, one of the qualities that made this project more riveting than other welldesigned initiatives was that the solution was more human. That is, it was designed to give equal time to the more creative and emotional right brain rather than exclusively looking at the fact-based left brain aspects of the business. The resulting intervention touched people in ways that seemed to draw them to solutions.

In fact, when two dozen HPT team members (out of a potential group of 34) were asked if they would participate in the development of a Think-a-Thon again, all said yes. Many cited positive elements (especially "friends" and "fun") as an unexpected benefit to the work. And as a consultant imagining an ideal client world, what could be better?

\section{AI AND THE HPT PROFESSIONAL}

Applying AI to HPT projects and efforts can help us live a more positive life (Van Tiem, Moseley, \& Dessinger, 2001, p. 270-275). Realizing that it is important to "walk the talk," we will learn to live by Cooperrider and Srivastva's five foundational principles and the sixth one added by Stavros and Torres (2005). 


\section{Constructionist Principle}

We need to understand and make sense of our experiences and how our decisions and actions interconnect to provide positive (or negative) meaning and energy.

No matter what the history may be, people and relationships are dynamic: they can thus be open to new developments and possibilities. Simply put, words and actions and the meaning we place on them create our world through language, conversations, and interactions with others. (Stavros and Torres, 2005, p. 53)

\section{Principle of Simultaneity}

As soon as we inquire about something, change begins to happen. Each question or comment moves the dynamics in one direction or the other. The cycle is continuous. We need to pose questions that lead to positive, not deficitbased, conversations.

\section{Poetic Principle}

Our life is like an open book and can be altered at any time. Each person's life story can be written, rewritten, altered, and adapted at any time. We need to focus on wisdom, joy, and strength.

\section{Anticipatory Principle}

"As human beings we are constantly planning, anticipating, musing, worrying, imaging, thinking, wondering, and designing" (Stavros \& Torres, 2005, p. 69). Our internal dialogue needs to anticipate positive future events. "A self-fulfilling prophecy can guide a person toward his or her expectations for blockbuster success or lackluster results" (Stavros \& Torres, 2005, p. 70). We must be willing to try to stretch and reach for our dreams.

\section{Positive Principle}

The more positive our images, thoughts, and dreams, the more we are likely to have positive and enriching experiences. We need to retain positive images of organizations, family, friends, and our colleagues. Great athletes provide success stories of their accomplishments while visualizing positive outcomes, heroic feats, and disciplined emotions.

\section{Principle of Awareness}

Self-reflective contemplation of our actions and the actions of others will provide insight for the future, leading to positive relationships and events. Awareness will help us realize the significance of daily occurrences and help us take

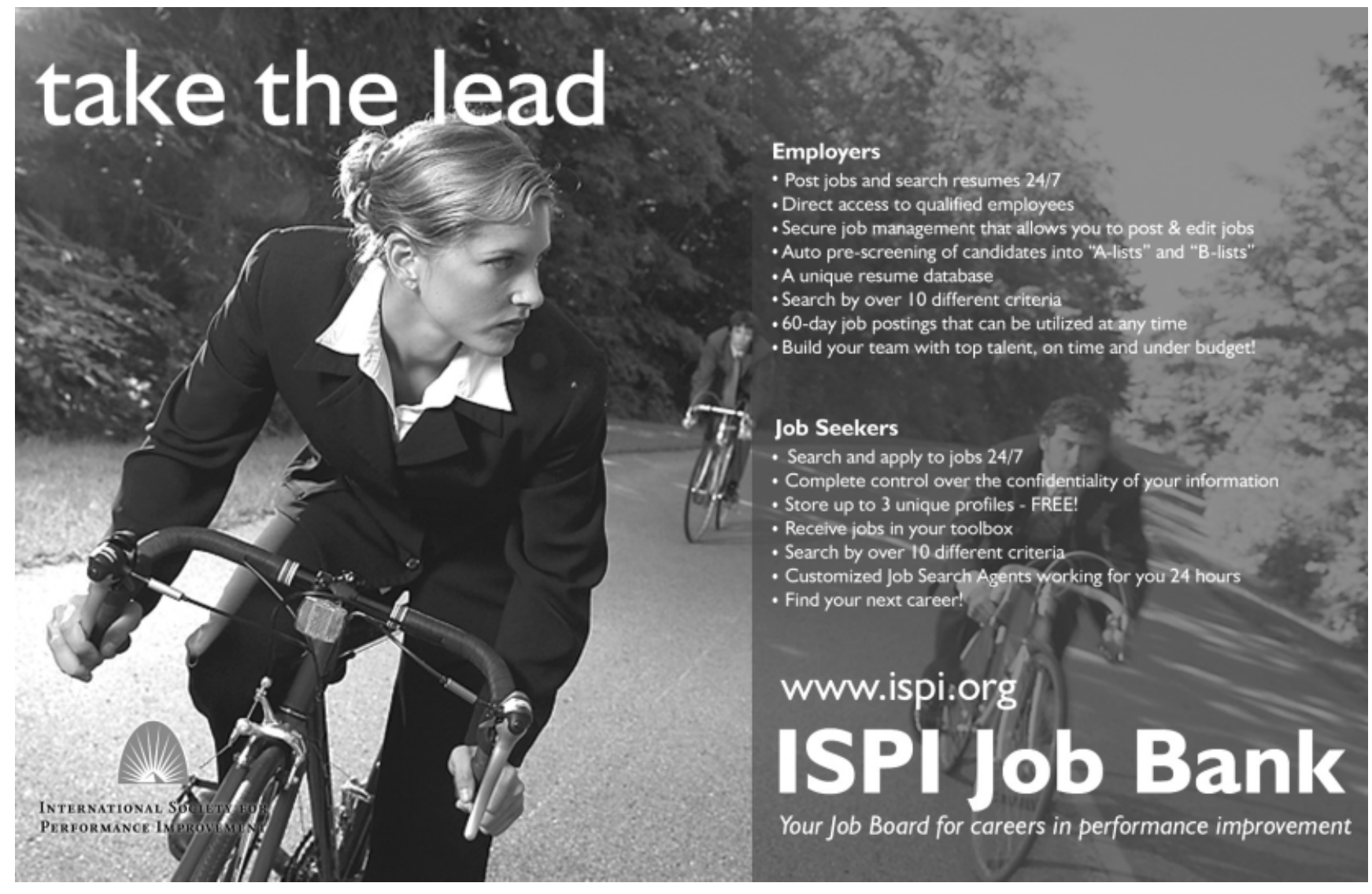


responsibility for the potential of society, community, organizations, colleagues, friends, and family.

Clearly HPT: Appreciative Approach offers enormous potential for changing a deficit-based problem-oriented approach to a more enriching, positive approach that offers hope and promise.

\section{References}

Brinkerhoff, R.O. (2003). The success case method. San Francisco: Berrett-Koehler.

Cooperrider, D.L., \& Whitney, D. (1998). A positive revolution in change: Appreciative inquiry. Unpublished manuscript. Retrieved March 6, 2006, from http://appreciativeinquiry .case.edu.

Cooperrider, D.L., Whitney, D., \& Stavros, J.M. (2003). Appreciative inquiry handbook: The first in a series of AI workbooks for leaders of change (pp. 14-17). Bedford Heights, OH:

Lakeshore Publishers.
Hammond, S.A. (1998). The thin book of appreciative inquiry (2nd ed.). Bend, OR: Thin Book.

Lewis, J., \& Van Tiem, D. (2004). Appreciative inquiry: A view of the glass half full. Performance Improvement, 43(8), 19-24. [DOI: 10:1002/pfi.4140430808.]

Stavros, J.M., \& Torres, C.B. (2005). Dynamic relationships: Unleashing the power of appreciative inquiry in daily living. Chagrin Falls, OH: Taos Institute Publishing.

Van Tiem, D.M., Moseley, J.L., \& Dessinger, J.C. (2001). Performance improvement interventions: Enhancing people, processes and organizations through performance technology. Silver Spring, MD: International Society for Performance Improvement.

Van Tiem, D.M., Moseley, J.L., \& Dessinger, J.C. (2004). Fundamentals of performance technology: A guide to improving people, process and performance (2nd ed.). Silver Spring, MD: International Society for Performance Improvement.

JENNIFER ROSENZWEIG, CPT, MEd, MPOD, is the global employee practice leader at Carlson Marketing Worldwide, where she develops strategic solutions targeted toward helping her clients improve their business results. She is a member of the Forum Board for People Performance Management and Measurement in association with Northwestern University. She is also a board member for the Employee Involvement Association. Recent publishing projects include coauthoring two ASTD Infolines, one on the topic of partnerships and the other on appreciative inquiry. In addition, she is one of 83 featured authors in the third edition of the Handbook of Human Performance Technology. Rosenzweig was among the first graduates of Case Western Reserve University's master's program in positive organizational development. She may be reached at jrosenzweig@Carlson.com.

DARLENE M. VAN TIEM, CPT, PhD, MSA, CPLP, is an associate professor emeritus and coordinator of the performance improvement and instructional design graduate program at the University of Michigan, Dearborn. In addition, she is on the adjunct faculty of Boise State University's instructional and performance technology graduate program. She was human resource director at Ameritech (now AT\&T) Yellow Pages for Michigan, Ohio, Indiana, and Wisconsin and curriculum manager for General Motors Technical Training (North America), including GM suppliers. She is the lead author of two best-selling ISPI award-winning books: Fundamentals of Performance Technology, second edition (2004), and Performance Improvement Interventions (2001). For the Handbook of Human Performance Technology (2006), she was lead author for three chapters and section editor. In addition, she coauthored two ASTD Infolines with Jennifer Rosenzweig. Van Tiem serves on the ISPI board of directors (2006-2008). She has been recognized by ASTD as National Technical Trainer of the Year (1992) and received the ASTD National Excellence in Leadership Award (1993). She has presented at approximately 75 international and state conferences and chapter meetings for ISPI, ASTD, Academy of Human Resource Development, American Association for Adult and Continuing Education, HRA, and National Association for Developmental Education. She may be reached at dvł@umd.umich.edu. 